\title{
Production of Activated Carbon From Sludge and Herb Residue of Traditional Chinese Medicine Industry and Its Application for Methylene Blue Removal
}

\author{
Zhenwei Yu, ${ }^{\mathrm{a}}$ Qi Gao, ${ }^{\mathrm{b}}$ Yue Zhang, ${ }^{\mathrm{a}}$ Dandan Wang, ${ }^{\mathrm{b}}$ Innocent Nyalala, ${ }^{\mathrm{a}}$ and \\ Kunjie Chen ${ }^{\mathrm{a}, *}$
}

\begin{abstract}
Sludge-based activated carbon (SAC) was prepared with sewage sludge and Chinese medicine herbal residues (CMHR's). An orthogonal experimental design method was used to determine the optimum preparation conditions. The effects of the impregnation ratio, activation temperature, activation time, and addition ratio of CMHR's on the iodine value and Brunauer-Emmett-Teller surface area of activated carbon were studied. X-ray diffraction, Fourier-transform infrared spectrometer, and scanning electron microscopy were used to characterize the prepared SAC. The results showed that the optimal process conditions for preparing the SAC were as follows: an impregnation ratio of $1: 4$, an activation time of $30 \mathrm{~min}$, an activation temperature of $700{ }^{\circ} \mathrm{C}$, and an addition ratio of CMHR's of $40 \%$. The adsorption balance of the methylene blue dye was examined at room temperature. Adsorption isotherms were obtained by fitting the data using the Langmuir and Freundlich models, which showed that methylene blue adsorption was most suitable for the Langmuir equation. The results demonstrated that SAC prepared from SS and CMHR's from a Chinese medicine factory could effectively expel dyes from wastewater.
\end{abstract}

Keywords: Format; Chinese medicine herbal residues; Sewage sludge; Activated carbon; Characterization

Contact information: a: College of Engineering, Nanjing Agricultural University, 40 Dianjiangtai Road, Nanjing, Jiangsu 210031, China; b: SPH Xing Ling Sci. \& Tech. Pharmaceutical Co., Ltd., 3500

Huqingping Road, Shanghai 201703, China; *Corresponding author: kunjiechen@njau.edu.cn

\section{INTRODUCTION}

Sewage sludge (SS) is an inevitable by-product of the sewage treatment process. Its production has been sharply increasing with the development of urbanization and industrialization (Smith et al. 2009). Meanwhile, SS is a type of colloidal sediment that contains harmful pollutants, including heavy metals, pathogens, and microorganisms. Nevertheless, the composition of SS may vary remarkably depending on the different raw materials and process. Textile sludge is one such example of this; it contains many chemical nutrients, heavy metals, and aromatic dyes (Sud et al. 2008). The main ingredient of sludge that is produced from paper mills is lignocellulose. Without proper disposal methods, SS can cause heavy environmental pollution. Many of the traditional methods, such as landfill, anaerobic fermentation, incineration, and so forth, used to treat SS can achieve specific and straightforward processing needs. However, these methods have drawbacks, such as waste of resources and environmental pollution. Therefore, it is important to find an effective and novel treatment method for the utilization of sludge (Devi and Saroha 2017). 
Chinese medicinal herbal residues (CMHRs) are the rejected materials formed from the production of Chinese medicinal herbs (CMHs). These residues, along with Chinese patent medicine and light chemical products of $\mathrm{CMH}$, mainly result from the bulk production of drug substances in pharmaceutical factories and drugstores (Gao et al. 2012). The CMHRs are abundant in organic substances. In China, more than 30 million tons of CMHRs are annually produced (Guo et al. 2013). Currently, the disposal methods of CMHRs are handled mainly through stacking, incinerating, and landfilling, which not only occupy a remarkable amount of land but also result in severe pollution of the environment and a colossal waste of resources. Thus, research into the recycling of CMHRs is important to improve the utilization of CMHRs, reduce resource waste, and promote the virtuous cycle of the Chinese medicinal herbal industry (Li et al. 2018).

Activated carbon (AC), a type of inert porous support material, is widely used for air purification and wastewater disposal due to its ability to distribute chemicals on sizeable hydrophobic interior surfaces (Luo et al. 2016). The frequently-used production methods involve physical activation and chemical activation. The advantages of chemical activation, which is more famous for combining carbonization and activation, include lower operating temperatures, high yields, more natural classification of the activating reagent, and a higher surface area (Liu and Zhao 2012). It is worth mentioning that Kemmer et al. (1971) first proposed the idea that sludge can be used for the preparation of AC. However, the Brunauer-Emmett-Teller (BET) surface area of the prepared AC is so low that the prepared AC made from SS is rarely used in industrial production. Some carbonaceous substances have been added to the sludge to enhance the quality of AC. Tay et al. (2001) mixed coconut shell with the sludge, and the BET surface area of the finished product remarkably increased (Mahapatra et al. 2012). There is no doubt that adding measureable materials in sludge can improve the performance of AC. In addition, the resources of waste and sludge have been utilized. However, in the study of the preparation of sludge-based activated carbon, research has not been conducted on the use of traditional Chinese medicine pharmaceutical sludge and traditional Chinese medicine residue as raw materials.

In this study, AC was prepared via the chemical activation of SS and medicinal residue taken from a traditional Chinese medicine factory, using phosphoric acid. The effects of activation temperature, activation time, impregnation ratio, and the addition of medicinal residue on the performance and the yield of AC were studied. The BET surface area and iodine adsorption value of $\mathrm{AC}$ were used as evaluation indexes for analysis, and the best preparation technology was determined. Scanning electron microscopy (SEM), Fourier transform infrared spectroscopy (FTIR), and X-ray diffraction (XRD) were used to characterize the final production. Adsorption isotherms were determined by an adsorption equilibrium experiment for methylene blue.

\section{EXPERIMENTAL}

\section{Materials}

The SS used in this study came from the wastewater treatment plant of Shanghai Apricot Science and Technology Pharmaceutical Co., Ltd. (Shanghai, China). The sewage treatment system used an activated sludge system for secondary processing. The sludge treatment was carried out using anaerobic digestion and a belt filter press, and the initial moisture content of the sludge was $81.6 \%$. The CMHRs were derived from dried ginkgo 
leaves that were soaked in $60 \%$ ethanol solution and then continuously steam-ventilated. After $6 \mathrm{~h}$, the mixture was filtered and rinsed to obtain the sediments. All of the reagents used in this experiment were analytical reagents. Meanwhile, distilled water was used to prepare the solution. The SS and CMHRs characterization results of proximate and ultimate analysis are shown in Table 1.

Table 1. The SS and CMHRs Characterization of Proximate and Ultimate Analysis

\begin{tabular}{|c|c|c|c|c|c|c|c|c|c|}
\hline \multirow{2}{*}{ Sample } & \multicolumn{4}{|c|}{ Proximate analysis/ \% } & \multicolumn{5}{c|}{ Ultimate analysis/ \% } \\
\cline { 2 - 11 } & $\mathrm{V}_{\mathrm{d}}$ & $\mathrm{FC}$ & $\mathrm{A}_{\mathrm{d}}$ & $\mathrm{M}_{\mathrm{d}}$ & $\mathrm{C}$ & $\mathrm{H}$ & $\mathrm{O}$ & $\mathrm{N}$ & $\mathrm{S}$ \\
\hline SS & 52.84 & 15.68 & 25.16 & 6.32 & 24.23 & 4.25 & 21.53 & 2.41 & 2.47 \\
\hline CMHR & 72.59 & 14.65 & 8.23 & 4.53 & 53.72 & 7.74 & 33.68 & 1.25 & 0.36 \\
\hline
\end{tabular}

$\mathrm{SS}=$ sewage sludge; CMHR = Chinese medicine herbal residues

\section{Preparation of $A C$}

The sludge was oven-dried at $110{ }^{\circ} \mathrm{C}$ until its weight was constant. After being cooled, it was crushed to a diameter of $<200 \mu \mathrm{m}$. The CMHRs were dried for $24 \mathrm{~h}$ in the oven at $80{ }^{\circ} \mathrm{C}$ and then crushed to a diameter of $<200 \mu \mathrm{m}$ after cooling. The above two samples were wholly mixed in a specified proportion to generate the precursors for preparation. A certain proportion of phosphoric acid solution was added (the mass fraction was 0.5 ), the samples were stirred, and then impregnated at room temperature for $24 \mathrm{~h}$. The samples were then placed in an oven at $110{ }^{\circ} \mathrm{C}$ for $12 \mathrm{~h}$. The dried samples were then placed into a tube furnace, with the heating rate set at $10{ }^{\circ} \mathrm{C} / \mathrm{min}$, and the activation temperature and activation time were adjusted according to the experimental needs. Both the heating and cooling processes required a nitrogen inlet, and the nitrogen flow rate was $60 \mathrm{~mL} / \mathrm{min}$ until the tube furnace cooled down. The finished products were crushed, moderate hydrochloric acid solution $(0.1 \mathrm{~mol} / \mathrm{L})$ was added, and the samples were shaken and washed with a shaker. After $12 \mathrm{~h}$, the sludge was washed with warm distilled water until a neutral $\mathrm{pH}$ was obtained. The final product was obtained after drying to constant weight at $110{ }^{\circ} \mathrm{C}$, ground to 200 -mesh sized particles, and stored in desiccators for adsorption experiments and characterization.

\section{Methods}

\section{Characterization of $A C$}

The specific surface area and pore volume tests were performed based on the measurements on the pore size of the obtained AC. The texture characteristics of the biochar derived from the sludge were analyzed at $77 \mathrm{~K}$ using a surface area and porosity analyzer (Tristar II 3020, Micromeritics, Shanghai, China). Nitrogen adsorption isotherms were used to calculate the surface area, pore volume, and average pore size. The multipoint Brunauer-Emmett-Teller method was used to calculate the surface area (Zhang and Luo, 2018). The iodine number is a technique that is used to determine the adsorption capacity of AC. The iodine value indicates the porosity of the AC, and it is defined as $1 \mathrm{~g}$ of carbon-adsorbed iodine at the $\mathrm{mg}$ level. The iodine value, with reasonable accuracy, can be used as an approximation of the surface area and microporosity of AC. It is a measure of the level of activity (a higher number resulted in higher activation).

An XRD analysis was used to determine the presence of inorganic components in AC. The X-ray diffractometer model used in this experiment was the XRD-6100 (Shimadzu, Tokyo, Japan). A FTIR analysis was used to study the functional groups on the 
surface of the material. The model of the spectrometer used in this paper was the Nicolet iN10 (Thermo Scientific, Nanjing, China) with a resolution of $4 \mathrm{~cm}^{-1}$ and an acquisition rate of $20 \mathrm{~min}^{-1}$. Spectra were obtained in the range of $4000 \mathrm{~cm}^{-1}$ to $400 \mathrm{~cm}^{-1}$. The SEM analysis was used to investigate the surface morphology and pore structure of the material (Kacan and Kutahyali 2012). The model of the device was a Shimadzu SS 550 (Shimadzu, Tokyo, Japan).

\section{Adsorption isotherm}

A total of $0.2 \mathrm{~g}$ of prepared AC was inserted into a dry $150-\mathrm{mL}$ Erlenmeyer flask and $50 \mathrm{~mL}$ of an absolute concentration of methylene blue solution was added. The initial concentrations of the methylene blue solutions in Erlenmeyer flasks A, B, C, D, E, and F were $50 \mathrm{mg} / \mathrm{L}, 100 \mathrm{mg} / \mathrm{L}, 200 \mathrm{mg} / \mathrm{L}, 300 \mathrm{mg} / \mathrm{L}, 400 \mathrm{mg} / \mathrm{L}$, and $500 \mathrm{mg} / \mathrm{L}$, respectively, without adjusting the $\mathrm{pH}$ of the solution. Glass stoppers were used to cover the flasks before they were placed in a constant temperature oscillator (temperature set to $30{ }^{\circ} \mathrm{C}$, with an oscillation frequency of $150 \mathrm{rpm}$ ) for $12 \mathrm{~h}$ until it reached equilibrium. The sample was separated from the solution via filtration through a $0.45-\mu \mathrm{m}$ filter. The filtrate was then placed in a cuvette with a light path of $1 \mathrm{~cm}$. The concentration of the filtrate was measured using an ultraviolet (UV) spectrophotometer with a wavelength of $665 \mathrm{~nm}$ (UV-Vis-2800, Unico, Shanghai, China). Each experiment was repeated under the same conditions. The adsorption capacity $q_{\mathrm{e}}(\mathrm{mg} / \mathrm{g})$ of $\mathrm{MB}$ adsorbed at equilibrium was determined from Eq. 1,

$$
q_{e}=\frac{\left(C_{0}-C_{e}\right) V}{w}
$$

where $C_{0}$ and $C_{\mathrm{e}}(\mathrm{mg} / \mathrm{L})$ are the liquid-phase concentrations of the dye initially and at equilibrium, respectively, $V(\mathrm{~L})$ is the volume of the solution, and $w(\mathrm{~g})$ is the mass of adsorbent used.

\section{Adsorption kinetics}

Add $3 \mathrm{~g} / \mathrm{L}$ of prepared $\mathrm{AC}$ to $150 \mathrm{mg} / \mathrm{L} \mathrm{MB}$ solution at room temperature, and shake them at $30,60,90,120,150,180,210,240,270,300,330,390,450$, and $510 \mathrm{~min}$, respectively, on the shaker, then filter them after shaking.

\section{Experimental Design}

By checking the relevant literature, it can be seen that the activation time, activation temperature, impregnation ratio, and addition ratio of CMHRs have specific effects on the pore structure and adsorption characteristics of the prepared AC during the preparation of sludge-based AC by phosphoric acid activation (Zhao and Zhou 2016). Therefore, the orthogonal test design method was used in this study to determine the influence level of various relevant factors in the preparation process of the sludge-based AC on the performance of the prepared AC, as well as to determine the best preparation process. The orthogonal experimental design method, a design method commonly used for multi-factor and multi-level tests, can perform a statistical analysis on the test results of a few experimental programs and obtain the optimal test plan and the impact of various factors on the evaluation index ( $\mathrm{Li}$ et al. 2016). Based on previous research results and relevant data, this study used the iodine value and BET specific surface area as evaluation indicators to determine the four-factor three-level orthogonal test $\mathrm{L}_{9}\left(3_{4}\right)$. The factors and levels of the orthogonal test are shown in Table 2. 
Table 2. Factors and Levels of the Orthogonal Experiment

\begin{tabular}{|c|c|c|c|c|}
\hline \multirow{2}{*}{ Level } & \multicolumn{4}{|c|}{ Factor } \\
\cline { 2 - 5 } & $\begin{array}{c}\text { Impregnation } \\
\text { Ratio }(\mathrm{mL} / \mathrm{g})\end{array}$ & $\begin{array}{c}\text { Activation Time } \\
(\mathrm{min})\end{array}$ & $\begin{array}{c}\text { Activation } \\
\text { Temperature }\left({ }^{\circ} \mathrm{C}\right)\end{array}$ & $\begin{array}{c}\text { Addition Ratio of } \\
\text { Dregs }(\%)\end{array}$ \\
\hline 1 & $1: 2$ & 30 & 500 & 20 \\
\hline 2 & $1: 3$ & 60 & 600 & 30 \\
\hline 3 & $1: 4$ & 90 & 700 & 40 \\
\hline
\end{tabular}

\section{RESULTS AND DISCUSSION}

\section{Results of Experimental Design}

Table 3. Results of the Orthogonal Experiment

\begin{tabular}{|c|c|c|c|c|c|c|}
\hline \multirow[b]{2}{*}{ No. } & A & B & $\mathrm{C}$ & $D$ & \multirow{2}{*}{$\begin{array}{l}\text { lodine } \\
\text { Value } \\
(\mathrm{mg} / \mathrm{g})\end{array}$} & \multirow{2}{*}{$\begin{array}{c}\text { BET } \\
\text { Specific } \\
\text { Surface } \\
\text { Area }\left(\mathrm{m}^{2} / \mathrm{g}\right)\end{array}$} \\
\hline & $\begin{array}{l}\text { Impregnation } \\
\text { Ratio }(\mathrm{mL} / \mathrm{g})\end{array}$ & $\begin{array}{l}\text { Activation } \\
\text { Time (min) }\end{array}$ & $\begin{array}{c}\text { Activation } \\
\text { Temperature } \\
\left({ }^{\circ} \mathrm{C}\right)\end{array}$ & $\begin{array}{c}\text { Addition } \\
\text { Ratio of } \\
\text { Dregs (\%) }\end{array}$ & & \\
\hline 1 & $1: 2$ & 90 & 500 & 20 & 502.96 & 894 \\
\hline 2 & $1: 4$ & 60 & 600 & 30 & 518.52 & 764 \\
\hline 3 & $1: 4$ & 90 & 700 & 40 & 696.31 & 957 \\
\hline 4 & $1: 3$ & 30 & 600 & 40 & 674.85 & 881 \\
\hline 5 & $1: 2$ & 60 & 500 & 40 & 526.54 & 808 \\
\hline 6 & $1: 4$ & 30 & 500 & 20 & 678.19 & 921 \\
\hline 7 & $1: 3$ & 60 & 700 & 20 & 534.08 & 876 \\
\hline 8 & $1: 2$ & 30 & 700 & 30 & 565.12 & 842 \\
\hline 9 & $1: 3$ & 90 & 500 & 30 & 508.57 & 754 \\
\hline
\end{tabular}

Table 3 shows the header design and experimental results. The data in Table 3 was subjected to orthogonal analysis, and the results are shown in Table 4 . The higher the range value, the more significant the influence of the factor on the index (Kacan 2016).

Table 4. Analysis of the Results of the Orthogonal Experiment

\begin{tabular}{|c|c|c|c|c|c|}
\hline \multirow{2}{*}{$\begin{array}{c}\text { Evaluation } \\
\text { Index }\end{array}$} & Analysis Item & $\mathrm{A}$ & $\mathrm{B}$ & $\mathrm{C}$ & $\mathrm{D}$ \\
\cline { 3 - 6 } & $\begin{array}{c}\text { Impregnation } \\
\text { Ratio }\end{array}$ & $\begin{array}{c}\text { Activation } \\
\text { Time }\end{array}$ & $\begin{array}{c}\text { Activation } \\
\text { Temperature }\end{array}$ & $\begin{array}{c}\text { Addition Ratio of } \\
\text { Dregs }\end{array}$ \\
\hline \multirow{4}{*}{$\begin{array}{c}\text { lodine Value } \\
(\mathrm{mg} / \mathrm{g})\end{array}$} & $\mathrm{k}_{1}$ & 531.54 & 639.39 & 571.1 & 571.74 \\
\cline { 2 - 6 } & $\mathrm{k}_{2}$ & 572.5 & 526.38 & 565.44 & 530.74 \\
\cline { 2 - 6 } & $\mathrm{k}_{3}$ & 631.01 & 569.28 & 598.50 & 632.57 \\
\hline \multirow{3}{*}{$\begin{array}{c}\text { BET Specific } \\
\text { Surface Area } \\
\left(\mathrm{m}^{2} / \mathrm{g}\right)\end{array}$} & $\mathrm{R}$ & 99.47 & 113.01 & 33.06 & 101.83 \\
\cline { 2 - 6 } & $\mathrm{k}_{1}$ & 848 & 881.33 & 827.67 & 897 \\
\cline { 2 - 6 } & $\mathrm{k}_{2}$ & 837 & 816 & 846.33 & 786.67 \\
\hline
\end{tabular}

Note: $\mathrm{K}_{\mathrm{i}}$ in the table is the sum of the index values for each factor at the same level; $\mathrm{k}_{i}$ is the average of the index values for each factor at the same level; $R$ is the range value, which is the difference between the maximum and minimum values of $k_{i}$ 
When the iodine value was used as an evaluation index, the primary and secondary factors were as follows: activation time (B) $>$ addition ratio of CMHRs (D) $>$ impregnation ratio $(\mathrm{A})>$ activation temperature $(\mathrm{C})$. A comparison of various factors showed that the optimal combination was $\mathrm{A}_{3} \mathrm{~B}_{1} \mathrm{C}_{3} \mathrm{D}_{3}$ when iodine value was used as the evaluation index.

When the BET surface area was used as an evaluation index, the primary and secondary factors were as follows: addition ratio of CMHRs (D) > activation time (B) > activation temperature $(\mathrm{C})>$ impregnation ratio (A). A comparison of the various factors showed that the optimal combination was $\mathrm{A}_{3} \mathrm{~B}_{1} \mathrm{C}_{3} \mathrm{D}_{1}$ when the BET surface area was used as the evaluation index.

In the experiment that used traditional Chinese medicine dregs to prepare sludgebased activated carbon, and influencing degrees of different factors varied with respect to each specific indicator. This was because the two methods differed in the measurement. The iodine adsorption value is mainly used to characterize the microporous structure of the $\mathrm{AC}$, which is only a part of the specific surface. It is mainly used to indicate the adsorption capacity of AC for small molecules. However, the BET surface area is the sum of the total external surface of all particles, and it reflected the adsorption capacity of AC. Therefore, the comprehensive balance method was used to determine the optimal program. For factors $\mathrm{A}, \mathrm{B}$, and $\mathrm{C}$, the optimal combination was $\mathrm{A}_{3} \mathrm{~B}_{1} \mathrm{C}_{3}$. Factor $\mathrm{D}$ was the most critical factor affecting the iodine value and should be given priority when determining the optimal level. For iodine value, $\mathrm{k}_{3}$ was $10.64 \%$ higher than $\mathrm{k}_{1}$, and the difference was obvious. However, for BET surface area, $\mathrm{k}_{1}$ was only $1.67 \%$ higher than $\mathrm{k}_{3}$, and the gap between these two was small. Considering the above, it would be better to choose $\mathrm{D}_{3}$. In summary, under the experimental conditions, the optimal process was as follows: impregnation ratio of 1:4, activation time of $30 \mathrm{~min}$, activation temperature of $700{ }^{\circ} \mathrm{C}$, and the addition ratio of CMHRs of $40 \%$.

The above optimal solution was obtained by orthogonal experimental results, but it requires further verification to determine whether it is the optimal process condition. The sludge-based AC prepared by the above-described optimal plan was marked as SAC. The iodine value and BET surface area were $738.47 \mathrm{mg} / \mathrm{g}$ and $972 \mathrm{~m}^{2} / \mathrm{g}$, respectively. These results showed that an orthogonal experiment could optimize the preparation process of AC.

\section{Characterization of AC \\ $X R D$ analysis}

The X-ray diffraction patterns of SS and SAC are shown in Fig. 1. There were two diffraction peaks of SS and SAC at approximately $2 \theta=22^{\circ}$ to $25^{\circ}$ and $42^{\circ}$ to $45^{\circ}$, which corresponded to the diffraction characteristic peaks of the carbon material (002) and the graphite surface (100), respectively (Mahapatra et al. 2012). The peaks showed that disordered graphite crystallites existed in both the SS and SAC. Compared with SS, the (002) peak of SAC was slightly shifted to the right, and the diffraction angle is increased by $2.188^{\circ}$. The interlayer spacing distance of SS and SAC could be calculated by Bragg's Law, which were $0.443,0.365 \mathrm{~nm}$, respectively. Therefore, the interfacial spacing $d_{002}$ of the SAC was reduced, and the degree of graphitization was enhanced. The intensity of the (100) diffraction peak of SAC was remarkably reduced because the activation process caused the structure of the graphite crystal to be destroyed and resulted in a predominantly disordered thin carbon sheet. At the same time, lower crystallite strength corresponded with higher orientation freedom of the graphite crystallites, which in turn resulted in more pores between the crystallites and higher activity of the AC. This caused a larger specific surface 
area and a more porous structure that allowed the AC to have a better adsorption property (Liu et al. 2014).

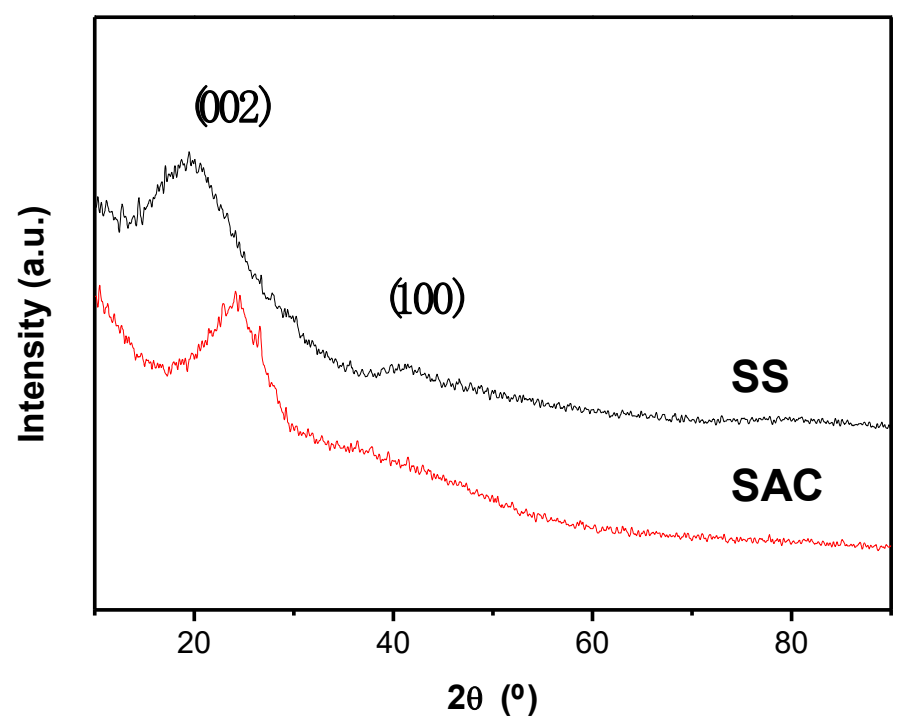

Fig. 1. XRD spectra of produced activated carbons and raw material

\section{FTIR analysis}

FTIR spectra were used to analyze the chemical structure and the change in functional groups of the samples (Puziy et al. 2003). Figure 2 shows a noticeable difference in the FTIR spectra between the SS and SAC. Compared with the SS, the number of absorption peaks in the SAC spectra was remarkably reduced. This was because some substances in the SS were decomposed and volatilized during the activation process. From previous studies, the broad and strong peak from 2500 to $3600 \mathrm{~cm}^{-1}$ found in SS clearly indicates the $-\mathrm{COOH}$ group. There is a deep broad absorption peak of around $3500 \mathrm{~cm}^{-1}$ to $3200 \mathrm{~cm}^{-1}$, which corresponds to the stretching vibration peak of the amino group (Sartova et al. 2018), and it can superimpose the stretching vibration peaks of the hydroxyl groups at $3500 \mathrm{~cm}^{-1}$ to $3300 \mathrm{~cm}^{-1}$. It can also be seen in Fig. 4 that SS and SAC had broad and robust absorption peaks near $3415 \mathrm{~cm}^{-1}$, which corresponded to the vibration peaks of -OH and $-\mathrm{NH}$. The stretching vibration peaks of methyl $\left(\mathrm{CH}_{3}\right)$ and methylene $\left(\mathrm{CH}_{2}\right)$ located at $2920 \mathrm{~cm}^{-1}$ and $2850 \mathrm{~cm}^{-1}$ correspond to the aliphatic hydrocarbons in SS (Pallarés et al. 2018). In the SAC spectrum, the intensity of two peaks was remarkably weakened, which indicated that the aliphatic hydrocarbons in SS were decomposed during the preparation process of AC. Between $1650 \mathrm{~cm}^{-1}$ to $1550 \mathrm{~cm}^{-1}$, both the SS and SAC had broad absorption peaks that corresponded to $\mathrm{C}=\mathrm{O}$ bonds. This indicated that both sample surfaces contained functional groups such as aldehydes, ketones, or carboxylic acids. However, the transmittance of SAC decreased and shifted slightly to the right. The spectrum of SS showed a broad peak at $1070 \mathrm{~cm}^{-1}$, which was caused by the stretching vibration of the C$\mathrm{O}-\mathrm{C}$ bond in the ether substance and completely disappeared after activation. The peaks at $670 \mathrm{~cm}^{-1}, 610 \mathrm{~cm}^{-1}$, and $490 \mathrm{~cm}^{-1}$ may be associated with conjugated $\mathrm{C}=\mathrm{C}$ and $\mathrm{C}=\mathrm{N}$ functional groups. In summary, the surface of the SAC contained functional groups, such as hydroxyl, aldehyde, aliphatic, and carboxylic acid groups, which can remove organic pollutants through complexation reactions or ion exchange reactions with organic substances. 


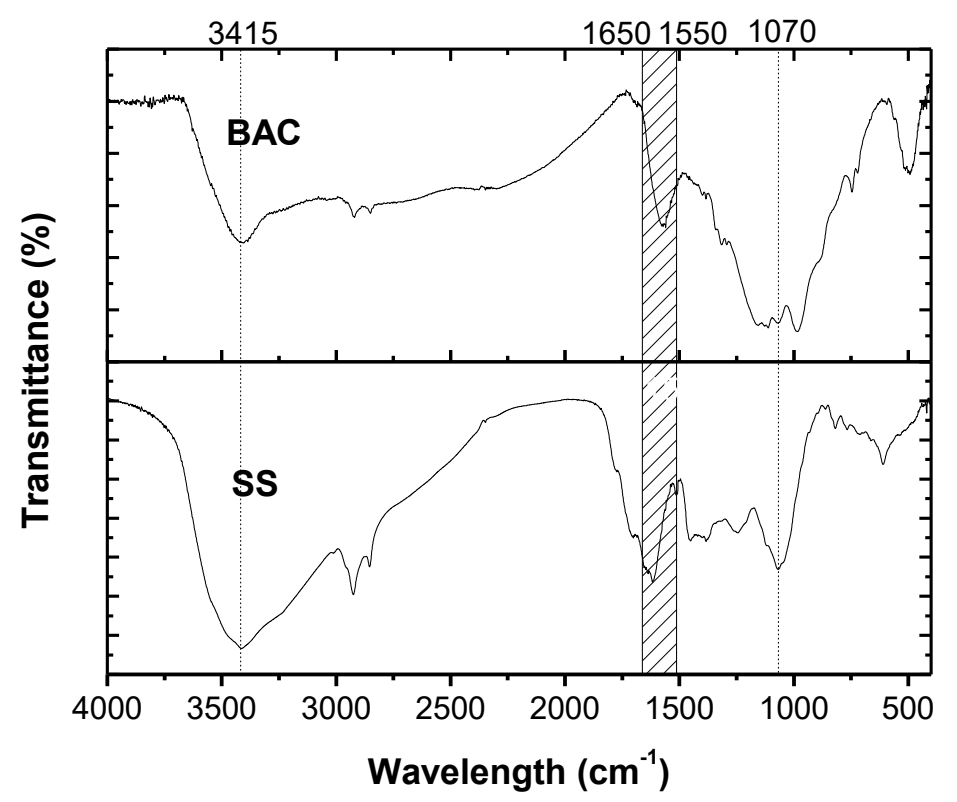

Fig. 2. FTIR spectra of produced activated carbons and raw material

\section{SEM analysis}

The surfaces of SS and SAC were observed via SEM, and the resulting photomicrographs are shown in Fig. 3. The structure of SS was dense, the surface was relatively flat, and there were few pore structures as shown in Fig. 3(a). After the pyrolysis and activation processes, the structure of SS changed remarkably and exhibited an irregular porous structure (Fig. 3(b)). The AC is a type of solid product formed from the carbonization and activation of biomass. During the pyrolysis process, certain cracks and pores form, which makes the structure loose and allows for the infiltration of phosphoric acid. Thus, the pore structure of the surface develops after phosphoric acid impregnation (Li et al. 2011).

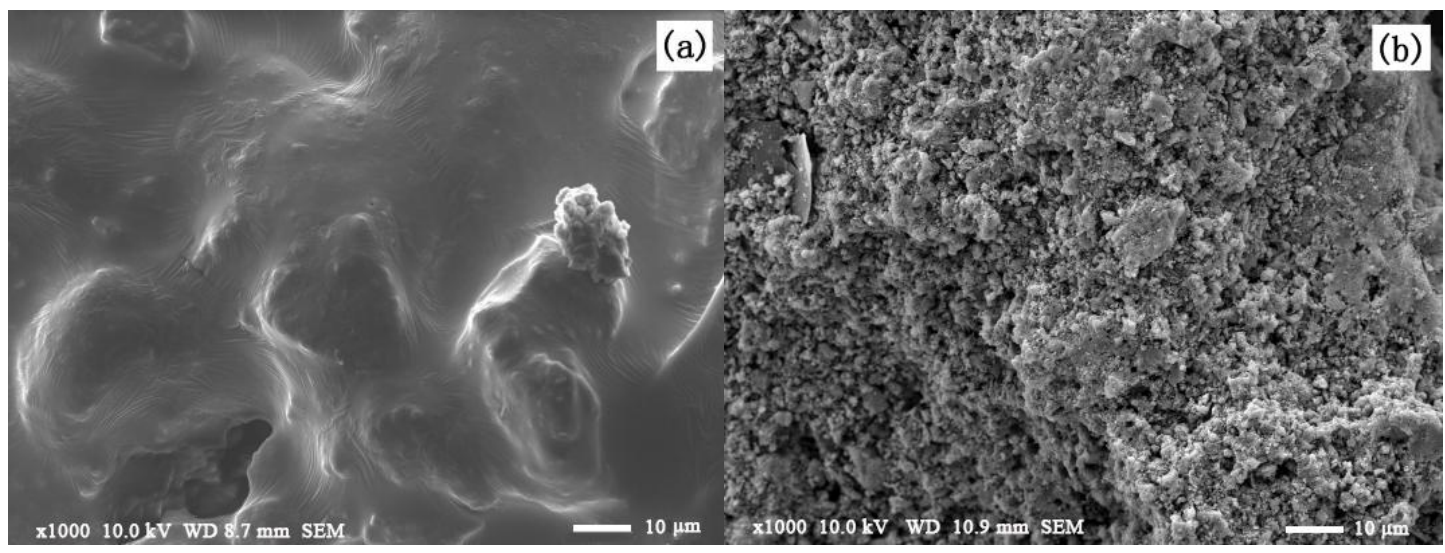

Fig. 3. SEM micrographs of (a) raw material and (b) produced activated carbons

The partial surface was honeycomb-shaped, with many microporous structures and a small number of mesoporous structures. The arrangement of the pore structure was relatively compact because the phosphoric acid entered the internal structure of the biomass carbon powder during activation. This caused the precursor of the biomass carbon to be 
minimized and then form a type of gas that escapes from materials when they are heated. Thereby, the pores were left in the AC, playing the role of the carbon skeleton. When the phosphoric acid was washed away, the carbon formed a porous structure. The difference in the surface morphology between the SS and SAC shows that chemical activation and high temperature pyrolysis play an important role in the formation and development of $\mathrm{AC}$ pore structure (Chen et al. 2017).

\section{Adsorption of AC}

The adsorption isotherm is the curve that describes how the adsorption capacity varies with equilibrium concentration (Leng et al. 2015). Under certain temperature conditions, the adsorption capacity increased with increasing adsorbent equilibrium concentration. The adsorption isotherm, which describes the relationship between the concentration of the adsorbed material on the adsorbent surface and the remaining material in the solution, provides an essential basis for the design and optimization of the adsorption system. Langmuir and Freundlich isotherm models were used in this study (Danish et al. 2013). The Langmuir isotherm model assumes that the surface of the adsorbent is homogeneous and that the adsorption method is monolayer adsorption. All of the adsorption sites have equal affinity and adsorption capability, and there is no interaction between the adsorbed adsorbates. The Freundlich isotherm model assumes that the adsorption occurs in an inhomogeneous surface and is multi-layered adsorption. The adsorption capacity of adsorbate increases infinitely, with increasing contaminant concentration (San Miguel et al. 2003). The analysis of adsorption equilibrium data is important for optimizing the adsorption system.

\section{Langmuir sorption isotherm}

The linear form of Langmuir's isotherm model is given by the following equation,

$$
\frac{C_{e}}{q_{e}}=\frac{1}{Q_{0} b}+\frac{1}{Q_{0}} C_{e}
$$

where $C_{\mathrm{e}}$ is the equilibrium concentration $(\mathrm{MB})$ of the adsorbate $(\mathrm{mg} / \mathrm{L}), q_{\mathrm{e}}$ is the amount of $\mathrm{MB}$ adsorbed per unit mass of adsorbent $(\mathrm{mg} / \mathrm{g})$, and $Q_{0}$ and $b$ are Langmuir constants relate to adsorption capacity and rate of adsorption. As is shown in Fig. 4, when $C_{\mathrm{e}} / q_{\mathrm{e}}$ was plotted against $C_{\mathrm{e}}$, a straight line with slope $1 / \mathrm{Q}_{0}$ was obtained, which indicated that the adsorption of MB of the samples followed the Langmuir isotherm (Rio et al. 2005). The constant values (' $b$ ' and ' $Q_{0}$ ') for the Langmuir model can be calculated from its isotherm. The values are given in Table 5.

Conversion of the experimental data to the Langmuir isotherm model indicated the homogeneity of AC. The results also showed that dye molecules formed a monolayer cover on the outer surface of the prepared AC (Wahab et al. 2010). The essential features of the Langmuir isotherm can be represented by the dimensionless equilibrium parameter $\left(R_{\mathrm{L}}\right)$, shown in Eq. 3,

$$
R_{L}=\frac{1}{1+b C_{0}}
$$

where $b$ is the Langmuir constant and $C_{0}$ is the highest dye concentration $(\mathrm{mg} / \mathrm{L})$. The value of $R_{\mathrm{L}}$ represents the type of isotherm and can be classified as unfavorable $\left(R_{\mathrm{L}}>\right.$ $1)$, linear $\left(R_{\mathrm{L}}=1\right)$, favorable $\left(0<R_{\mathrm{L}}<1\right)$, or irreversible $\left(R_{\mathrm{L}}=0\right)$. From the 
experimental data, the value of $R_{\mathrm{L}}$ was 0.151 , which indicated that the samples facilitated the adsorption of MB under the conditions of this study.

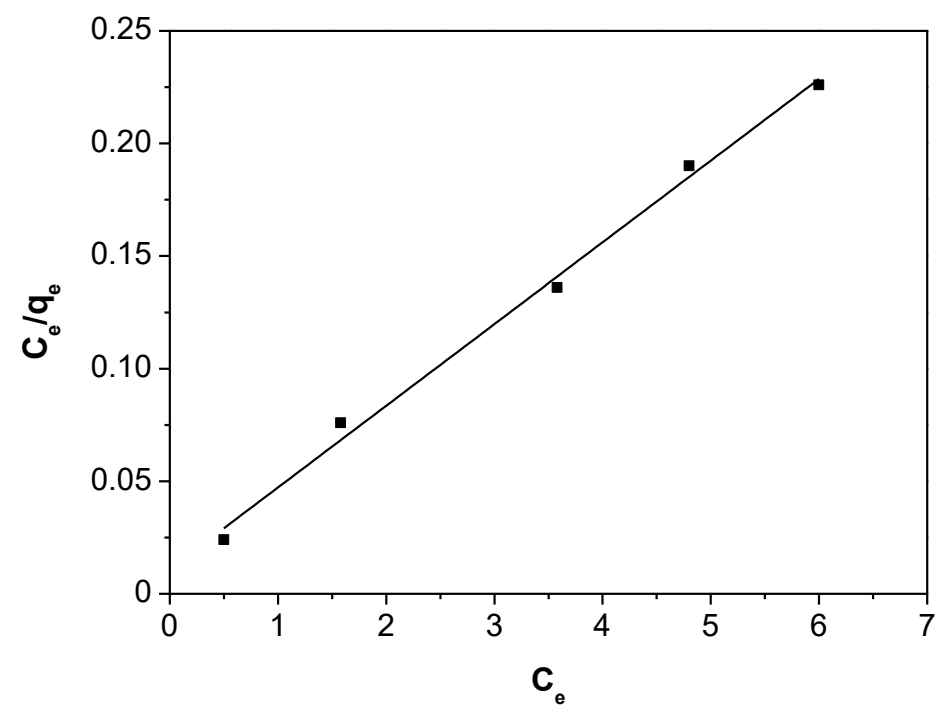

Fig. 4. Langmuir adsorption isotherm of SAC adsorption of MB

\section{Freundlich sorption isotherm}

The linear form of the Freundlich isotherm model can be given by the following equation,

$$
\lg q_{e}=\lg K_{F}+\frac{1}{n} \lg C_{e}
$$

where $Q_{\mathrm{e}}$ is the equilibrium adsorption capacity $(\mathrm{mg} / \mathrm{g}), C_{\mathrm{e}}$ is the adsorbate equilibrium concentration (MB), $K_{\mathrm{F}}$ and $n$ are Freundlich constants, $K_{\mathrm{F}}(\mathrm{mg} / \mathrm{g})$ is the adsorption capacity of the adsorbent and indicates the amount of dye adsorbed on the adsorbent per unit equilibrium concentration, and $n$ indicates the strength of the adsorption process; $1 / n$ is the slope of a straight line, and it is an index that measures the strength of adsorption or surface unevenness.

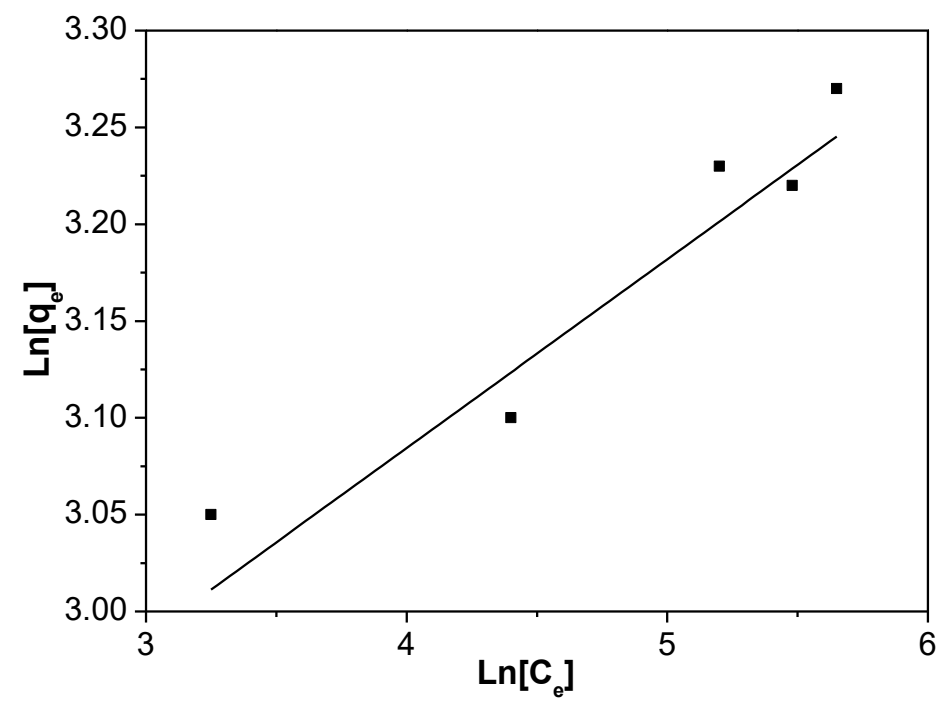

Fig. 5. Freundlich adsorption isotherm of $S A C$ adsorption of $M B$ 
When the value of $1 / n$ is $<1$, it indicates a standard Freundlich isotherm. However, when the value of $1 / n$ is $>1$, it means that the adsorption is synergistic (Xiao et al. 2014). As shown in Fig. 5, the straight line of $1 \mathrm{~g}$ of $q_{\mathrm{e}}$ to $1 \mathrm{~g}$ of $C_{\mathrm{e}}$ obtained in experimental data had a slope of $1 / n$, which indicated that the adsorption of $\mathrm{MB}$ conformed to the Freundlich isotherm.

Therefore, the Freundlich constants $\left(K_{\mathrm{F}}\right.$ and $\left.n\right)$ can be obtained from the experimental data. The parameter values and associated correlation coefficients of two isotherms are listed in Table 5. The value of $\mathrm{R}^{2}$, measuring the overall fitting degree of the regression equation, expresses the overall relationship between the dependent variables and all independent variables. The maximum value of $R^{2}$ is 1 . A value of $R^{2}$ closer to 1 indicates a better fitting degree of the regression line to the observations (Mahapatra et al. 2012). The value of the correlation coefficient indicated that the Langmuir model $\left(\mathrm{R}^{2}=0.993\right)$ produced a better fit than the Freundlich model $\left(\mathrm{R}^{2}=0.718\right)$.

Table 5. Langmuir and Freundlich Sorption Isotherm at $\mathrm{MB}$ at $30{ }^{\circ} \mathrm{C}$

\begin{tabular}{|c|c|c|c|c|c|c|c|}
\hline \multirow{2}{*}{ Sample } & \multicolumn{4}{|c|}{ Langmuir Sorption Isotherm } & \multicolumn{3}{c|}{ Freundlich Sorption Isotherm } \\
\cline { 2 - 8 } & $Q_{0}(\mathrm{mg} / \mathrm{g})$ & $b(\mathrm{~L} / \mathrm{mg})$ & $\mathrm{R}^{2}$ & $R_{\mathrm{L}}$ & $1 / n$ & $K_{\mathrm{F}}(\mathrm{mg} / \mathrm{g})$ & $\mathrm{R}^{2}$ \\
\hline SAC & 26.99 & 0.208 & 0.993 & 0.151 & 0.0935 & 17.35 & 0.718 \\
\hline
\end{tabular}

\section{Adsorption kinetics}

The Lagergren pseudo-first-order kinetic equation and the pseudo-second-order kinetic equation can be given by the following equation,

$$
\begin{aligned}
& \ln \left(Q_{e}-Q_{t}\right)=\ln Q_{e}-t K_{1} \\
& t / Q_{t}=1 /\left(K_{2} Q_{e}^{2}\right)+t / Q_{e}
\end{aligned}
$$

where $Q_{\mathrm{e}}$ is the adsorption amount at adsorption equilibrium state $(\mathrm{mg} / \mathrm{g}) ; Q_{\mathrm{t}}$ is the adsorption amount at time $t(\mathrm{mg} / \mathrm{g}) ; K_{1}$ is the pseudo-first-order rate constant $\left(\mathrm{min}^{-1}\right)$; and $K_{2}$ is the pseudo-second-order rate constant $\left(\mathrm{min}^{-1}\right)$.

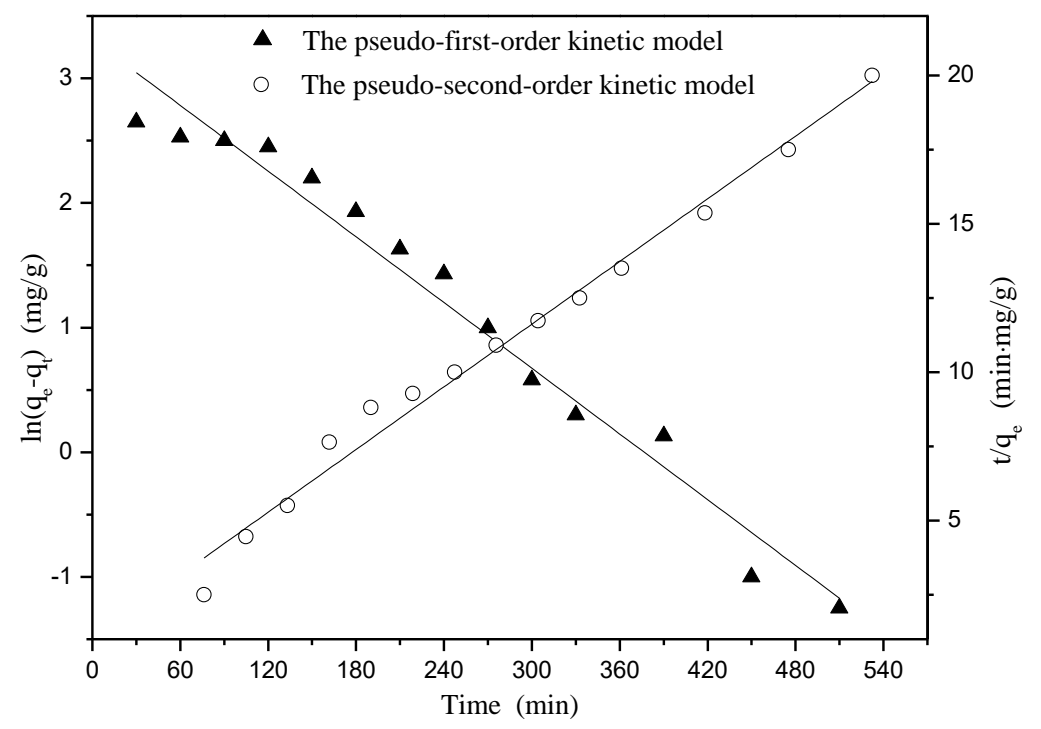

Fig. 6 Fit line of kinetic equation 
The pseudo-first-order kinetic model and the pseudo-second-order kinetic model were used to simulate the adsorption process that SAC adsorb MC, and the fitting curve was obtained as shown in Fig. 6 The kinetic parameters, obtained using slope and intercept calculations, are shown in Table 6.

It can be seen from Table 6 that the two kinetic equations resulted in high fitting degree to the adsorption process of this experiment, and both can describe the kinetics of SAC adsorption on MB. The pseudo-second-order kinetic equation achieved a better fitting effect on the adsorption of methylene blue $\left(\mathrm{R}^{2}=0.985\right)$. In summary, the Lagergren pseudosecond-order kinetic equation can more closely describe the kinetic process of SAC on MB.

Table 6. Fitting Parameters of Kinetic Equations

\begin{tabular}{|c|c|c|c|c|c|c|}
\hline \multirow{2}{*}{$C_{0}(\mathrm{mg} / \mathrm{L})$} & \multicolumn{2}{|c|}{ Pseudo-first-order kinetic model } & \multicolumn{2}{c|}{ Pseudo-second-order kinetic model } \\
\cline { 2 - 7 } & $q_{e}(\mathrm{mg} / \mathrm{g})$ & $K_{1}$ & $\mathrm{R}^{2}$ & $q_{e}(\mathrm{mg} / \mathrm{g})$ & $K_{2}$ & $\mathrm{R}^{2}$ \\
\hline 150 & 28.37 & 0.00879 & 0.969 & 29.52 & 0.03344 & 0.985 \\
\hline
\end{tabular}

\section{CONCLUSIONS}

1. The results of this study showed that it is feasible to prepare AC using SS and CMHRs from Chinese medicine factories through phosphoric acid activation. Orthogonal experiments evaluated the effects of the immersion ratio, activation temperature, activation time, and the addition ratio of dregs on the iodine value and BET surface area of SAC.

2. The optimal conditions for preparing SAC were as follows: impregnation ratio of 1:4, activation time of $30 \mathrm{~min}$, activation temperature of $700{ }^{\circ} \mathrm{C}$, and the addition ratio of dregs of $40 \%$. The iodine value and BET surface area of prepared SAC obtained under these conditions were $738 \mathrm{mg} / \mathrm{g}$ and $972 \mathrm{~m}^{2} / \mathrm{g}$, respectively.

3. The data showed that methylene blue adsorption was most suitable for the Langmuir equation. The research has shown that the prepared sludge-based AC can be effectively used for the decolorization of dye wastewater, which can reduce the treatment burden of SS and CMHRs.

\section{ACKNOWLEDGMENTS}

The authors wish to acknowledge the financial support from Nanjing Agricultural University.

\section{REFERENCES CITED}

Chen, J., Zhang, L., Yang, G., Wang, Q., Li, R., Lucia, L. A. (2017). "Preparation and Characterization of activated carbon from hydrochar by phosphoric acid activation and its adsorption performance in prehydrolysis liquor," BioResources 12(3), 5928- 
5941. DOI:10.15376/biores.12.3.5928-5941

Danish, M., Hashim, R., Ibrahim, M. N. M., and Sulaiman, O. (2013). "Characterization of physically activated Acacia mangium wood-based carbon for the removal of methyl orange dye," BioResources 8(3), 4323-4339. DOI: 10.15376/biores.8.3.43234339

Devi, P., and Saroha, A. K. (2017). "Utilization of sludge based adsorbents for the removal of various pollutants: A review," Science of The Total Environment 578, 1633. DOI:10.1016/j.scitotenv.2016.10.220

Gao, H. W., Ma, D. D., and Xu, G. (2012). "Medicinal plant acid-treatment for a healthier herb tea and recycling of the spent herb residue," RSC Advances 2(14), 5983-5989. DOI: $10.1039 / \mathrm{C} 2 \mathrm{RA} 20429 \mathrm{~K}$

Guo, F., Dong, Y., Dong, L., and Jing, Y. (2013). "An innovative example of herb residues recycling by gasification in a fluidized bed," Waste Management 33(4), 825832. DOI: 10.1016/j.wasman.2012.12.009

Kacan, E., and Kutähyali, C. (2012). "Adsorption of strontium from aqueous solution using activated carbon produced from textile sewage sludges," Journal of Analytical and Applied Pyrolysis 97, 149-157. DOI: 10.1016/j.jaap.2012.06.006

Kacan, E. (2016). "Optimum BET surface areas for activated carbon produced from textile sewage sludges and its application as dye removal," Journal of Environmental Management 166, 116-123. DOI: 10.1016/j.jenvman.2015.09.044

Kemmer, F. N., Robertson, S. R., and Mattix, R. D. (1971). "Sewage treatment process," US Patent Office, Patent No. 3619420

Leng, L., Yuan, X., Zeng, G., Shao, J., Chen, X., Wu, Z., Wang, H., and Peng, X. (2015). "Surface characterization of rice husk bio-char produced by liquefaction and application for cationic dye (Malachite green) adsorption," Fuel 155, 77-85. DOI: 10.1016/j.fuel.2015.04.019

Li, H., Li, X., Liu, L., Li, K., Wang, X., and Li, H. (2016). "Experimental study of microwave-assisted pyrolysis of rice straw for hydrogen production," International Journal of Hydrogen Energy 41(4), 2263-2267. DOI: 10.1016/j.ijhydene.2015.11.137

Li, T., Guo, F., Li, X., Liu, Y., Peng, K., Jiang, X., and Guo, C. (2018). "Characterization of herb residue and high ash-containing paper sludge blends from fixed bed pyrolysis," Waste Management 76, 544-554. DOI: 10.1016/j.wasman.2018.04.002

Li, W. H., Yue, Q. Y., Gao, B. Y., Wang, X. J., Qi, Y. F., Zhao, Y. Q., and Li, Y. J. (2011). "Preparation of sludge-based activated carbon made from paper mill sewage sludge by steam activation for dye wastewater treatment," Desalination 278(1-3), 179-185. DOI: 10.1016/j.desal.2011.05.020

Liu, B. S., Wang, W. S., Wang, N., and Au, C. T. (2014). "Preparation of activated carbon with high surface area for high-capacity methane storage," Journal of Energy Chemistry 23(5), 662-668. DOI: 10.1016/S2095-4956(14)60198-4

Luo, Y., Street, J., Steele, P., Entsminger, E., and Guda, V. (2016). "Activated carbon derived from pyrolyzed pinewood char using elevated temperature, $\mathrm{KOH}, \mathrm{H}_{3} \mathrm{PO}_{4}$, and $\mathrm{H}_{2} \mathrm{O}_{2}$," BioResources 11(4), 10433-10447.

Mahapatra, K., Ramteke, D. S., and Paliwal, L. J. (2012). "Production of activated carbon from sludge of food processing industry under controlled pyrolysis and its application for methylene blue removal," Journal of Analytical and Applied Pyrolysis 95, 79-86. DOI: 10.1016/j.jaap.2012.01.009

Pallarés, J., González-Cencerrado, A., and Arauzo, I. (2018). "Production and characterization of activated carbon from barley straw by physical activation with 
carbon dioxide and steam," Biomass and Bioenergy 115, 64-73. DOI:

10.1016/j.biombioe.2018.04.015

Puziy, A. M., Poddubnaya, O. I., Martínez-Alonso, A., Suárez-García, F., and Tascón, J. M. D. (2003). "Synthetic carbons activated with phosphoric acid III. Carbons prepared in air," Carbon 41(6), 1181-1191. DOI: 10.1016/S0008-6223(03)00031-9

Rio, S., Faur-Brasquet, C., Le Coq, L., Courcoux, P., and Le Cloirec, P. (2005).

"Experimental design methodology for the preparation of carbonaceous sorbents from sewage sludge by chemical activation--Application to air and water treatments," Chemosphere 58(4), 423-437. DOI: 10.1016/j.chemosphere.2004.06.003

San Miguel, G., Fowler, G. D., and Sollars, C. J. (2003). "A study of the characteristics of activated carbons produced by steam and carbon dioxide activation of waste tyre rubber," Carbon 41(5), 1009-1016. DOI: 10.1016/S0008-6223(02)00449-9

Sartova, K., Omurzak, E., Kambarova, G., Dzhumaev, I., Borkoev, B., and Abdullaeva, Z. (2018). "Activated carbon obtained from the cotton processing wastes," Diamond and Related Materials 91, 90-97. DOI:10.1016/j.diamond.2018.11.011

Sud, D., Mahajan, G., and Kaur, M. P. (2008). "Agricultural waste material as potential adsorbent for sequestering heavy metal ions from aqueous solutions - A review," Bioresource Technology 99(14), 6017-6027. DOI: 10.1016/j.biortech.2007.11.064

Tay, J. H., Chen, X. G., Jeyaseelan, S., and Graham, N. (2001). "A comparative study of anaerobically digested and undigested sewage sludges in preparation of activated carbons," Chemosphere 44(1), 53-57. DOI: 10.1016/s0045-6535(00)00384-2

Wahab, M. A., Jellali, S., and Jedidi, N. (2010). "Ammonium biosorption onto sawdust: FTIR analysis, kinetics and adsorption isotherms modeling," Bioresource Technology 101(14), 5070-5075. DOI: 10.1016/j.biortech.2010.01.121

Xiao, X., Chen, B., and Zhu, L. (2014). "Transformation, morphology, and dissolution of silicon and carbon in rice straw-derived biochars under different pyrolytic temperatures," Environmental Science Technology 48(6), 3411-3419. DOI: $10.1021 / \mathrm{es} 405676 \mathrm{~h}$

Zhang, D., and Luo, R. (2018). "Modifying the BET model for accurately determining specific surface area and surface energy components of aggregates," Construction and Building Materials, 175, 653-663. DOI: 10.1016/j.conbuildmat.2018.04.215

Zhao, S., and Zhou, T. (2016). "Biosorption of methylene blue from wastewater by an extraction residue of Salvia miltiorrhiza Bge," Bioresource Technology 219, 330-337. DOI: 10.1016/j.biortech.2016.07.121

Article submitted: September 19, 2018; Peer review completed: November 26, 2018; Revised version received: December 2, 2018; Accepted: December 15, 2018; Published: January 7, 2019.

DOI: 10.15376/biores.14.1.1333-1346 